\title{
Association of anti-Chlamydia antibodies with ectopic pregnancy in Benin city, Nigeria: a case-control study
}

\author{
Agholor $\mathrm{K}^{2},{ }^{*}$ Omo-Aghoja L ${ }^{3}$, Okonofua $\mathrm{F}^{1,2}$
}

\author{
1. Departments of Obstetrics and Gynecology, University of Benin and University of Benin Teaching Hospital, \\ Benin city \\ 2. Women's Health and Action Research Centre, Benin city \\ 3. Department of Obstetrics and Gynaecology, Delta State University, Abraka
}

\begin{abstract}
Background: Ectopic pregnancy remains a major public health problem especially in many developing countries where it is a significant contributor to pregnancy related morbidity and mortality

Objective: To determine the association between prior Chlamydia trachomatis infection and the risk of ectopic pregnancy.

Methods: A case-control study from two tertiary health care facilities in Benin City, Nigeria. Ninety eight women with ectopic pregnancy (cases) and another 98 women with uncomplicated intrauterine pregnancy (controls) matched for age, were interviewed using a semi-structured questionnaire and evaluated for serological evidence of prior Chlamydia trachomatis infection.

Results: The antibody titres in cases $(48 \%)$ were significantly higher than in controls $(16.3 \%)(\mathrm{p}<0.001)$. However, the association between Chlamydia antibodies and ectopic pregnancy was attenuated when the effects of indicators of previous pelvic infections, socio-demographic characteristics, contraceptive and sexual history were controlled for. Primary level of education $(\mathrm{OR}=6.32 ; \mathrm{CI}, 2.31-17.3)$, three or more lifetime sexual partners $(\mathrm{OR}=5.71 ; \mathrm{CI}, 2.39-13.65)$ and prior history of vaginal discharge $(\mathrm{OR}=5.00 ; \mathrm{CI}, 2.03-12.3)$ were more likely to be associated with ectopic pregnancy than with the presence of antibodies to Chlamydia trachomatis (OR $=2.82 ; 95 \%$ CI, $1.33-5.95)$. The Population Attributable Risk was $30.9 \%$.
\end{abstract}

Conclusion: Chlamydial infections play only a limited role in the pathogenesis of ectopic pregnancy.

Key words: anti-chlamydia antibodies, ectopic pregnancy, sexual history, vaginal discharge, level of education

African Health Sciences 2013; 13(2): 430 - 440 http:/ /dx.doi.org/10.4314/ahs.v13i2.33

\section{Introduction}

Ectopic pregnancy remains a major public health problem especially in many developing countries where it is a significant contributor to pregnancy related morbidity and mortality ${ }^{1,2}$. This view is sustained by its rising incidence globally ${ }^{3-7}$. Recent work from Benin City, Nigeria suggests that the trend in ectopic pregnancy incidence was that of a yearly rise $^{1}$. Observed increases in ectopic pregnancy have been attributed to several factors, including increase in the incidence of pelvic infections and improvement in the diagnostic techniques for ectopic pregnancy ${ }^{4}$. Its increasing incidence globally, has resulted in growing interest in its aetiology $\mathrm{y}^{8,9}$.

A number of studies have looked at the antibody responses induced by Chlamydia trachomatis

*Corresponding author:
Dr. Lawrence Omo-Aghoja
College of Health Sciences
Delta State University
Abraka, Nigeria
Mobile: 234 (0)8039377043
Email: eguono_2000@yahoo.com

infection and have generally found a good correlation between serum antibodies to Chlamydia trachomatis and ectopic pregnancy ${ }^{9-12}$. In addition, ectopic pregnancy risk was observed to be greatest amongst a subset of women with multiple exposures to chlamydial infections ${ }^{13}$. These reports conclude that Chlamydia trachomatis infection is a major cause of fallopian tube damage which predisposes to ectopic pregnancy. However, recent Scandinavian studies show divergent results concerning the association of ectopic pregnancy with prior Chlamydia trachomatis infection ${ }^{14-17}$.

Whereas the Norwegian studies found a significant association between previous Chlamydia trachomatis infection and subsequent ectopic pregnancy ${ }^{14,17}$, a reduced risk of ectopic pregnancy after Chlamydia trachomatis infection was reported from Denmark ${ }^{15}$ and no association was found in the Swedish study ${ }^{16}$. A recent review of these findings suggests that the explanation for the discrepant results is the inclusion of women with diagnosed and hence presumably treated infections in these Scandinavian registry 
studies ${ }^{18}$. Again, Andersen et $\mathrm{al}^{19}$ speculated that the results may be explained by failure to adjust for confounders such as sexual behaviour and contraceptive use in these studies. This underscores the need for new studies on Chlamydia trachomatis infection and ectopic pregnancy which (as highlighted by Bakken ${ }^{18}$ in his review of recent epidemiological findings on the association of Chlamydia trachomatis and ectopic pregnancy) are few.

We hypothesized that a higher proportion of women with ectopic pregnancy had serological evidence of previous infection with Chlamydia trachomatis as compared to pregnant controls without previous ectopic pregnancy. Our study therefore aims to ascertain the association between serological evidence of prior Chlamydia trachomatis infections and the risk of ectopic pregnancy. The result will be useful in designing programmes to help reduce the burden of Chlamydia trachomatis genital infections and by extension ectopic pregnancy.

\section{Methods}

This case-control study was conducted in the two main referral hospitals for gynecologic emergencies in Benin City - the University of Benin Teaching Hospital, and the Central Hospital. The two hospitals attend to $>80 \%$ of the gynaecological and obstetric caseloads in Benin City and its environs. The cases were 98 consecutive women with a diagnosis of ectopic pregnancy confirmed at laparotomy in these two hospitals during the period January 2010-June 2010.

The study was approved by the Ethical Review Committee of the University of Benin Teaching Hospital.

In all cases, the diagnosis of ectopic pregnancy was confirmed by histological evaluation of the extirpated Fallopian tube specimen. Women using an intrauterine contraceptive device (IUCD) at the time of conception as well as those who had blood transfusion within 6 months of the study were excluded from the study. The control group was made up of women with confirmed uncomplicated second trimester intrauterine pregnancy, without a history of previous ectopic pregnancy, attending the antenatal clinic of the aforementioned health facilities. This group was made up of women without a history of infertility, tubal surgery or miscarriage. Each case of ectopic pregnancy was immediately followed by an age matched ( \pm 2 years) pregnant control attending the antenatal clinic.

\section{Data collection}

Informed consent was obtained from both cases and controls upon recruitment into the study. They were interviewed using a semi-structured questionnaire. The questionnaire elicited information on socio-demographic variables, sexual and reproductive risk factors. In particular, the following information was obtained: age, marital status, educational level, and parity. Other information solicited included, gestational age, age at sexual debut, number of sexual partners, use of intrauterine contraceptive device, history of previous ectopic pregnancies, previous history suggestive of pelvic inflammatory disease and abdomino-pelvic surgery. Macroscopic evidence of previous pelvic infection (adhesions) was recorded at the time of the operation.

\section{Serological assay}

Serological assay was performed with $5 \mathrm{ml}$ (millilitre) of venous blood which was collected from the volar surface of the forearms of both cases and controls and entered into clean and sterile plain specimen bottle. The specimen was collected before blood transfusion in patients with ectopic pregnancy. All specimens were analyzed in the Medical Microbiology and Parasitology Laboratory of the University of Benin Teaching Hospital, by Medical Microbiologists who worked in collaboration with the authors. The blood specimen was allowed to clot, and then centrifuged to obtain sera. The sera were stored frozen at $-20^{\circ} \mathrm{C}$ until analyzed in batches for serum Chlamydia antibodies. The serological assay was done using the Immunocomb Chlamydia trachomatis Immunoglobulin G kit (Orgenics, Israel), an indirect solid-phase enzyme immunoassay (EIA) test that quantitatively measures antibodies to Chlamydia trachomatis in human serum. The reagent test kit was brought to room temperature and then $10 \mu \mathrm{L}$ (microlitre) pipetted serum was assayed with reagent control samples for Chlamydia trachomatis antibodies. The procedure was then run through a number of timed steps as outlined by the manufacturer. The results were recorded with the aid of calorimetric calibration scale in titres. The tests were validated with the control samples. Significant titre (positive results) was recorded as 1 in 32 or greater.

\section{Data management and analysis}

Data analysis was done using the Statistical Package for the Social Sciences (SPSS) version 16. The results were aggregated and presented 
in statements, frequency distribution tables and cross tables. Statistical test of association was carried out where applicable and the level of significance set at $\mathrm{p}<0.05$. Univariate analysis of socio-demographic characteristics, contraceptive and sexual history, as well as prevalence of Chlamydia antibodies in patients with ectopic gestation and pregnant controls were also done. Conditional logistic regression was used to calculate the odds ratio and 95\% confidence intervals. The characteristics of women with Chlamydia antibodies were analyzed in univariate logistic regression models. Multivariate conditional logistic regression was used to determine the association between Chlamydia antibodies and ectopic pregnancy while controlling for the effects of background characteristics.

\section{Results}

\section{Women's Socio-demographic Characteristics}

A total of 98 women with a diagnosis of ectopic pregnancy (cases), confirmed at laparotomy, matched with 98 pregnant controls were enrolled into the study. Both groups were similar with regard to age: the mean \pm SD age for cases and controls was 28.3 \pm 3.4 years. The mean gestational age at presentation for the ectopic pregnant patient was seven weeks (range, 6-11 weeks) while the mean gestational age at recruitment for the intrauterine pregnant controls was 19.1 weeks (range, $16-25$ weeks). The women with ectopic pregnancies were significantly more likely to be single, more likely to be nulliparous, have less than tertiary level education and are non-professionals when compared with controls. There were nine cases of repeat ectopic pregnancies giving a recurrent ectopic pregnancy rate of $9.2 \%$.

\section{Sexual History}

The mean age at sexual debut for the women with ectopic pregnancy was $18.6 \pm 2.0$ years which contrasted significantly with pregnant controls with a mean age of $22.1 \pm 4.5$ years $(p=0.00)$. Moreover, women with ectopic pregnancy were more likely to be at 13-17 years at sexual debut relative to $\geq 18$ years in comparison with controls. In addition, $50.0 \%$ (49/98) of women with ectopic pregnancy reported having had three or more sexual partners in their lifetime, compared with pregnant controls in which $16.3 \%(16 / 98)$ reported three or more lifetime sexual partners. This difference was found to be statistically significant $(p<0.001)$. Despite this finding, contraceptive uptake was poor in the study population. The comparisons of the demographic and sexual history between the ectopic and intrauterine pregnant patients are shown in table 1.

\section{Indicators of pelvic infection}

Among the ectopic pregnant patients, 85.7\% (84/ 98) had at least one marker of previous pelvic infection: vaginal discharge, lower abdominal pain, dyspareunia and dysmenorrhea. By contrast, 58.2\% (57/98) of the pregnant controls reported previous experience of indicators of pelvic infections. This difference was statistically significant $(p=0.02)$. The strongest differential between women with ectopic pregnancies and pregnant controls was found for vaginal discharge $(p=0.01)$.

\section{Prevalence of Chlamydia antibodies}

As shown in table 2, ectopic pregnant patients also had a higher prevalence of exposure to Chlamydia trachomatis $(48.0 \%)$ as evidenced by the presence of antibodies to Chlamydia trachomatis than did pregnant controls $(16.3 \%)$. The difference was statistically significant $(\mathrm{p}<0.001)$.

The attributable risk percent (AR\%) of ectopic pregnancy arising from a positive Chlamydia $\mathrm{IgG}$ was calculated using the formular ${ }^{20}$ :

$$
A R \%=\frac{I_{e}-I_{u}}{I_{e}} \times 100
$$

Where $\mathrm{AR} \%=$ the percent of the incidence of a disease in the exposed that is due to the exposure. It is the proportion of the incidence of a disease in the exposed that would be eliminated if exposure were eliminated:

$\mathrm{I}_{\mathrm{u}}=$ incidence in the unexposed $=16.3$

$\mathrm{I}_{\mathrm{e}}=$ incidence in the exposed $=48.0$

$$
\begin{aligned}
& \frac{48-16.3}{48} \times 100 \\
& =\quad 66.0 \%
\end{aligned}
$$

While the population attributable risk (PAR\%) was calculated using the formular ${ }^{21}$ :

$\operatorname{PAR} \%=\frac{\left.\right|_{\mathrm{p}}-\left.\right|_{\mathrm{u}}}{\left.\right|_{\mathrm{p}}} \times 100$

Where $\mathrm{PAR} \%=$ the percent of the incidence of a disease in the population (exposed and nonexposed) that is due to exposure. It is the percent of the incidence of a disease in the population that would be eliminated if exposure were eliminated.

$I_{p}=$ the incidence in total population (exposed and unexposed $)=23.6\left(\right.$ From Darougar et a $\left.{ }^{22}\right)$ 
$I_{u}=$ the incidence in the unexposed

$$
\begin{aligned}
& \frac{23.6-16.3}{23.6} \times 100 \\
& =30.9 \%
\end{aligned}
$$

\begin{tabular}{|c|c|c|c|c|c|}
\hline \multirow[t]{2}{*}{ Parameter } & \multicolumn{2}{|c|}{ Ectopic Pregnancy } & \multicolumn{2}{|c|}{ Intrauterine Pregnancy } & \multirow[t]{2}{*}{ P value } \\
\hline & $\mathbf{n}$ & $\%$ & $\mathbf{n}$ & $\%$ & \\
\hline Total & 98 & & 98 & & \\
\hline \multicolumn{6}{|l|}{ Age (years) } \\
\hline $20-24$ & 4 & 4.1 & 4 & 4.1 & \\
\hline $25-29$ & 63 & 64.3 & 63 & 64.3 & \\
\hline $30-34$ & 21 & 21.4 & 21 & 21.4 & \\
\hline $35-39$ & 10 & 10.2 & 10 & 10.2 & \\
\hline Mean age ( \pm SD in yrs) & $28.3 \pm 3.4$ & & $28.3 \pm 3.4$ & & \\
\hline \multicolumn{6}{|l|}{ Marital status } \\
\hline Single & 35 & 35.7 & $\mathrm{O}$ & 0.0 & 0.001 \\
\hline Married & 63 & 64.3 & 98 & 100.0 & \\
\hline \multicolumn{6}{|l|}{ Parity } \\
\hline 0 & 49 & 50.0 & 29 & 29.6 & 0.004 \\
\hline$\geq 1$ & 49 & 50.0 & 69 & 70.4 & \\
\hline \multicolumn{6}{|l|}{ Education } \\
\hline Primary & 35 & 35.7 & 0 & 0.0 & 0.001 \\
\hline Secondary & 49 & 50.0 & 16 & 16.3 & \\
\hline Tertiary & 14 & 14.3 & 82 & 83.7 & \\
\hline \multicolumn{6}{|c|}{ Indicators of Pelvic Infection } \\
\hline \multicolumn{6}{|c|}{ Vaginal discharge } \\
\hline \multicolumn{6}{|l|}{ Yes } \\
\hline No & 63 & 64.3 & 45 & 45.9 & 0.010 \\
\hline Lower abdominal pain & 35 & 35.7 & 53 & 54.1 & \\
\hline \multicolumn{6}{|l|}{ Yes } \\
\hline No & 14 & 14.3 & 21 & 21.4 & 0.192 \\
\hline Dysmenorrhoea & 84 & 85.7 & 77 & 78.6 & \\
\hline \multicolumn{6}{|l|}{ Yes } \\
\hline No & 49 & 50.0 & 37 & 37.8 & 0.084 \\
\hline Dyspareunia & 49 & 50.0 & 61 & 62.2 & \\
\hline \multicolumn{6}{|l|}{ Yes } \\
\hline \multirow[t]{2}{*}{ No } & 21 & 21.4 & 20 & 20.4 & 0.861 \\
\hline & 77 & 78.6 & 78 & 79.6 & \\
\hline \multicolumn{6}{|c|}{ No. of life time sexual partners } \\
\hline 1 or 2 & 49 & 50.0 & 82 & 83.7 & 0.001 \\
\hline$\geq 3$ & 49 & 50.0 & 16 & 16.3 & \\
\hline \multicolumn{6}{|l|}{ Age at sexual debut } \\
\hline $13-17$ & 21 & 21.4 & 9 & 9.2 & 0.017 \\
\hline$\geq 18$ & 77 & 78.6 & 89 & 90.8 & \\
\hline Mean \pm SD & $18.6 \pm 2.0$ & & $22.11 \pm 4.5$ & & 0.001 \\
\hline \multicolumn{6}{|l|}{ Condom use } \\
\hline Never & 63 & 64.3 & 78 & 79.6 & 0.017 \\
\hline Occasionally or always & 35 & 35.7 & 20 & 20.4 & \\
\hline \multicolumn{6}{|l|}{ OCP } \\
\hline Never & 84 & 85.7 & 90 & 91.8 & 0.175 \\
\hline Occasionally or always & 14 & 14.3 & 8 & 8.2 & \\
\hline
\end{tabular}

Table 1: Characteristics of ectopic pregnant patients and intrauterine pregnant controls

OCP $=$ Oral contraceptive pills

\begin{tabular}{|c|c|c|c|c|c|}
\hline \multirow{2}{*}{ Antibody } & \multicolumn{2}{|c|}{ Cases } & \multicolumn{2}{|c|}{ Control } & \multirow{2}{*}{ P-value } \\
\hline & $\mathrm{n}$ & $\%$ & $\mathrm{n}$ & $\%$ & \\
\hline Total & 98 & & 98 & & \\
\hline Positive & 47 & 48.0 & 16 & 16.3 & 0.001 \\
\hline Negative & 51 & 52.0 & 82 & 83.7 & \\
\hline
\end{tabular}

Table 2: Prevalence of antibodies to Chlamydia trachomatis in cases compared with controls 


\section{Characteristics of women with Chlamydia antibodies}

Further analysis of the cases and controls showed that the prevalence of anti-chlamydia antibodies was significantly greater in ectopic pregnant patients (when compared with controls) with a higher number of life time sexual partners, to be $13-17$ years at sexual debut relative to $\geq 18$ years and more likely to have less than tertiary education as shown in table 3. Among the 49 (50\%) women with ectopic pregnancy who reported having had three or more sexual partners in their lifetime, $33(70.2 \%)$ were positive for Chlamydia trachomatis, whereas of the 16 (16.3\%) pregnant controls who reported a similar history of sexual activity, only $4(25.0 \%)$ were seropositive for
Chlamydia trachomatis $(\mathrm{p}=0.002)$. Table 3 also shows that, among the ectopic pregnant patients (compared with controls), anti-chlamydia antibodies were more likely to be present in parous women relative to nulliparous, and these women were also more likely never to have used a condom or oral contraceptive pills. These associations were not statistically significant. Of the indicators of pelvic infection, only dysmenorrhea had a significant correlation with positive antibodies to Chlamydia trachomatis antibodies $(\mathrm{p}=0.002)$. Vaginal discharge, lower abdominal pain and dyspareunia were not significantly associated with Chlamydia antibodies. Of the nine patients with repeat ectopic pregnancies, only two were positive for antibodies to Chlamydia trachomatis

Table 3: Characteristics of women with antibodies to Chlamydia trachomatis $(n=63)$

\begin{tabular}{|c|c|c|c|c|c|}
\hline \multirow[t]{2}{*}{ Parameter } & \multicolumn{2}{|c|}{ Cases } & \multicolumn{2}{|c|}{ Controls } & \multirow[t]{2}{*}{ P value } \\
\hline & $\mathrm{n}=47$ & $\%$ & $n=16$ & $\%$ & \\
\hline \multicolumn{6}{|l|}{ Parity } \\
\hline 0 & 21 & 44.7 & 4 & 25 & 0.165 \\
\hline$\geq 1$ & 26 & 55.3 & 12 & 75 & \\
\hline \multicolumn{6}{|l|}{ Education } \\
\hline Primary & 28 & 59.6 & 0 & 0.0 & 0.001 \\
\hline Secondary & 19 & 40.4 & 4 & 25.0 & \\
\hline Tertiary & 0 & 0.0 & 12 & 75.0 & \\
\hline \multicolumn{6}{|l|}{ Condom use } \\
\hline Never & 34 & 73.2 & 8 & 50.0 & 0.102 \\
\hline Occasionally or always & 13 & 27.7 & 8 & 50.0 & \\
\hline \multicolumn{6}{|l|}{ OCP } \\
\hline Never & 40 & 14.9 & 16 & 100.0 & 0.102 \\
\hline Occasionally or always & 7 & 85.1 & 0 & 0.0 & \\
\hline \multicolumn{6}{|c|}{ No. of life time sexual } \\
\hline partners & 14 & 29.8 & 12 & 75.0 & 0.002 \\
\hline 1 or 2 & 33 & 70.2 & 4 & 25.0 & \\
\hline \multicolumn{6}{|l|}{$\geq 3$} \\
\hline \multicolumn{6}{|l|}{ Age at sexual debut } \\
\hline $13-17$ & 14 & 29.8 & 0 & 0.0 & 0.013 \\
\hline$\geq 18$ & 33 & 70.2 & 16 & 100.0 & \\
\hline \multicolumn{6}{|l|}{ Vaginal discharge } \\
\hline Yes & 22 & 46.8 & 8 & 50.0 & 0.825 \\
\hline No & 25 & 53.2 & 8 & 50.0 & \\
\hline \multicolumn{6}{|l|}{ Lower abdominal pain } \\
\hline Yes & 14 & 29.8 & 4 & 25.0 & 0.714 \\
\hline No & 33 & 70.2 & 12 & 75.0 & \\
\hline \multicolumn{6}{|l|}{ Dysmenorrhoea } \\
\hline Yes & 33 & 70.2 & 4 & 25.0 & 0.002 \\
\hline No & 14 & 29.8 & 12 & 75.0 & \\
\hline \multicolumn{6}{|l|}{ Dyspareunia } \\
\hline Yes & 12 & 25.5 & 8 & 50.0 & 0.069 \\
\hline No & 35 & 74.5 & 8 & 50.0 & \\
\hline
\end{tabular}

$\mathrm{OCP}=$ Oral contraceptive pills 
Association of Chlamydia antibody with previous history of induced abortion

Among the ectopic pregnant patients, 57.1\% (56/ 98) self-reported a previous history of induced abortion. Of these, 33 (58.9\%) were positive for Chlamydia antibodies.

Peritubal adhesions and antibodies to Chlamydia trachomatis

Pelvic adhesions were visualized in 56 (57.1\%) women diagnosed with ectopic pregnancy at laparotomy. The relationship between this finding and antibodies to Chlamydia trachomatis is shown in table 4 . Severe adhesions were significantly associated with increasing antibody titre, while women with no adhesions had lower antibody titres $(\mathrm{p}<0.001)$. However, it is noteworthy to mention that $21(21.3 \%)$ of these women had a history of previous abdominal surgeries.

\section{Multivariate logistic regression analysis}

The results of the bivariate analysis show that women with ectopic pregnancy in comparison with controls were more likely to be seropositive for exposure to Chlamydia trachomatis, more likely to be single, have less than tertiary level education, more likely to have a higher level of sexual activity, more likely to indicate a previous history of vaginal discharge, more likely to be nulliparous and are non-professionals. Similarly, ectopic pregnant women who were seropositive for antibodies to Chlamydia trachomatis were more likely to have a higher number of life time sexual partners, less than tertiary education, more likely to be $13-17$ years at sexual debut relative to $\geq 18$ years, to report previous induced abortion and a history of dysmenorrhea.

The results of logistic regression (table 5) revealed more than four-fold increase in the risk of ectopic pregnancy in those with antibodies to Chlamydia trachomatis $(\mathrm{OR}=4.5$; $\mathrm{CI} 2.33-8.83)$ when controlling for the markers of pelvic infections. However, the association between Chlamydia antibodies (OR = 2.82; 95\% CI, 1.33 - 5.95) and ectopic pregnancy was attenuated when the effects of markers of prior pelvic infections, socio-demographic characteristics, contraceptive and sexual history were controlled for. Women with primary level of education $(\mathrm{OR}=6.32$; CI, 2.31 - 17.3), with three or more lifetime sexual partners $(\mathrm{OR}=5.71 ; \mathrm{CI}, 2.39-13.65)$ and who had a prior history of vaginal discharge $(\mathrm{OR}=5.00$; CI, 2.03 - 12.3) were more likely to present with ectopic pregnancy than women with antibodies to Chlamydia trachomatis.

Table 4: Association of antibodies to Chlamydia trachomatis with pelvic adhesions

\begin{tabular}{|c|c|c|c|c|c|c|}
\hline \multirow{2}{*}{$\begin{array}{c}\text { Severity of pelvic } \\
\text { adhesions }\end{array}$} & \multicolumn{6}{|c|}{ Serology Titre } \\
\hline & $<1 / 16$ & $1 / 16$ & $1 / 32$ & $1 / 64$ & $1 / 128$ & $1 / 256$ \\
\hline Normal pelvis & $7(33.3 \%)$ & $23(76.7 \%)$ & $0(0.0 \%)$ & $12(46.2 \%)$ & $0(0.0 \%)$ & $0(0.0 \%)$ \\
\hline $\begin{array}{l}\text { Grade I Pelvic } \\
\text { adhesions }\end{array}$ & $7(33.3 \%)$ & $0(0.0 \%)$ & $0(0.0 \%)$ & $0(0.0 \%)$ & $0(0.0 \%)$ & $0(0.0 \%)$ \\
\hline $\begin{array}{l}\text { Grade II Pelvic } \\
\text { adhesions }\end{array}$ & $7(33.3 \%)$ & $7(23.3 \%)$ & $7(100.0 \%)$ & $14(53.8 \%)$ & $7(100.0 \%)$ & $7(100.0 \%)$ \\
\hline
\end{tabular}

Table 5: $\quad$ Predictors of ectopic pregnancy: results of multivariate analysis

\begin{tabular}{lll}
\hline \multicolumn{1}{c}{ Parameter } & \multicolumn{1}{c}{$\begin{array}{c}\text { Model 1 } \\
\text { OR (95\% CI) }\end{array}$} & \multicolumn{1}{c}{$\begin{array}{c}\text { Model 2 } \\
\text { OR (95\% CI) }\end{array}$} \\
\hline Chlamydia antibodies & & \\
Yes & $4.50(2.33-8.83)$ & $2.82(1.33-5.95)$ \\
No & 1.00 & 1.00 \\
Education & & \\
Primary & & $6.32(2.31-17.31)$ \\
Secondary & $0.16(0.58-0.43)$ \\
Tertiary & 1.00 \\
Parity & \\
0 & & 1.00 \\
$\geq 1$ & & $1.52(0.68-3.34)$ \\
\hline
\end{tabular}




\begin{tabular}{|c|c|c|}
\hline Parameter & $\begin{array}{c}\text { Model } 1 \\
\text { OR }(95 \% \mathrm{CI}) \\
\end{array}$ & $\begin{array}{c}\text { Model } 2 \\
\text { OR }(95 \% \text { CI })\end{array}$ \\
\hline \multicolumn{3}{|l|}{ Age at sexual debut } \\
\hline $13-17$ & & $2.81(1.02-7.75)$ \\
\hline$\geq 18$ & & 1.00 \\
\hline \multicolumn{3}{|c|}{ No. of lifetime sexual partners } \\
\hline 1 or 2 & & 1.00 \\
\hline$\geq 3$ & & $5.71(2.39-13.65)$ \\
\hline \multicolumn{3}{|l|}{ Condom use } \\
\hline Never & & $2.25(0.96-5.29)$ \\
\hline Occasionally or always & & 1.00 \\
\hline \multicolumn{3}{|l|}{ OCP } \\
\hline Never & & $1.15(0.37-3.58)$ \\
\hline Occasionally or always & & 1.00 \\
\hline \multicolumn{3}{|c|}{ Previous induced abortion } \\
\hline Yes & & $2.67(1.16-6.13)$ \\
\hline No & & 1.00 \\
\hline \multicolumn{3}{|c|}{ Previous ectopic gestation } \\
\hline Yes & & $0.29(0.06-1.49)$ \\
\hline No & & 1.00 \\
\hline \multicolumn{3}{|l|}{ Vaginal discharge } \\
\hline Yes & $2.12(1.20-3.76)$ & $5.0(2.03-12.31)$ \\
\hline No & 1.00 & 1.00 \\
\hline \multicolumn{3}{|l|}{ Lower abdominal pain } \\
\hline Yes & $1.64(0.78-3.44)$ & $2.53(0.80-7.99)$ \\
\hline No & 1.00 & 1.00 \\
\hline \multicolumn{3}{|l|}{ Dysmenorrhoea } \\
\hline Yes & $1.65(0.93-2.91)$ & $2.34(1.26-4.36)$ \\
\hline No & 1.00 & 1.00 \\
\hline \multicolumn{3}{|l|}{ Dyspareunia } \\
\hline Yes & $1.06(0.53-2.12)$ & $2.56(1.26-5.20)$ \\
\hline No & 1.00 & 1.00 \\
\hline
\end{tabular}

OCP $=$ Oral contraceptive pill

\section{Discussion}

This study was designed to determine the association between ectopic pregnancy and previous exposures to Chlamydia trachomatis in Nigerian women. The exact aetiology of ectopic pregnancy remains unknown and is surrounded in most part by controversy. Yet, ectopic pregnancy continues to contribute to poor reproductive performance amongst women of child bearing age in our community ${ }^{1,2}$. However, evidence suggests an association between pelvic inflammatory disease and ectopic pregnancy ${ }^{1,3}$. Efforts at identifying the linkage, therefore, should attract priority attention as its identification will encourage the development of realistic policies to address the problem.

We hypothesized that a higher proportion of women with ectopic pregnancy will have serological evidence of previous infection with
Chlamydia trachomatis as compared to pregnant controls without previous ectopic pregnancy. The results of the present study demonstrated an association between ectopic pregnancy and the presence of Chlamydia antibodies in the women investigated. The prevalence of serum antibodies to Chlamydia trachomatis in women with ectopic pregnancy in this study was $48.0 \%$, while it was $16.3 \%$ in women with normal intrauterine pregnancy. Thus, the prevalence of serum antibodies to Chlamydia trachomatis was high among patients with ectopic pregnancy and significantly higher compared with women with an uncomplicated intrauterine pregnancy. This high rate is in keeping with data presented in local studies and compares favourably with various reports worldwide that patients with ectopic pregnancy are more likely to have 
immunoglobulin $\mathrm{G}(\mathrm{IgG})$ antibodies against Chlamydia trachomatis when compared with pregnant controls $^{9-12,23}$.

In addition, the results indicate that ectopic pregnant women who were seropositive for exposure to Chlamydia trachomatis had an increased prevalence of pelvic adhesions compared with ectopic patients who were negative for Chlamydia antibodies. There was also, as has been previously reported $^{24}$, a significant association between the severities of tubal damage with regards to pelvic adhesions and increasing antibody titre. This implies that increasing antibody titres are quantitatively related to both the presence of tubal damage and the severity of tubal damage. While it can be argued that the history of previous abdominal surgeries reported by about a quarter of these women might be contributory to the high rate of pelvic adhesions, the correlation of severity of pelvic adhesions with rising antibody cannot be explained by the effect of previous surgery alone. Indeed data from a comparative analysis of a large population of infertile women concluded that chlamydia antibody titres are of predictive value in the detection of tubal damage and are quantitatively related to the severity of damage ${ }^{24}$.

Given the large sample size of this study, in comparison with previous Nigerian studies, these data strongly support the association between the Chlamydia trachomatis and ectopic gestation and further implicate antibodies to Chlamydia trachomatis in the aetiology of tubal disease and/or ectopic pregnancy. Interestingly, the results of the attributable and population attributable risk and the multivariate conditional logistic regression model suggest otherwise. The attributable risk percent, a tool used extensively by epidemiologists, which is the proportion of the incidence of a disease in the exposed that would be eliminated if exposure were eliminated, was used to estimate the proportion of ectopic pregnancies associated with and possibly caused by chlamydial infection ${ }^{20}$. The attributable risk amongst our patients who were chlamydial antibody positive shows that 66 per cent of their ectopic pregnancies were associated with exposure to chlamydial infection. However, the most important estimate from a public health perspective is the population attributable risk, which measures the proportion of all ectopic gestations associated with chlamydial infection ${ }^{21}$. Previous studies have reported population attributable risks showing that 61,56 and 71 per cent of ectopic pregnancies are associated with chlamydial infection ${ }^{23,25,26}$. This contrasts sharply with the findings of this study where the population attributable risk was $30.9 \%$. Such unusually low value, though not unique to our population ${ }^{27}$, suggests that chlamydial infections play only a minor role in the pathogenesis of ectopic pregnancy.

Furthermore, Chlamydia trachomatis is certainly not the only cause of ectopic pregnancy as demonstrated by the absence of antibodies to Chlamydia trachomatis in $52 \%$ of ectopic pregnant patients. Moreover, only two of the nine patients who had a recurrent ectopic pregnancy were seropositive for Chlamydia antibodies. The suggestion that Chlamydia infection may play a less than significant role in the aetiology of ectopic pregnancy was again evident from the results of the multivariate conditional logistic regression where the strength of association between ectopic pregnancy and Chlamydia antibodies was attenuated when the effects of indicators of pelvic infections, sociodemographic characteristics, contraceptive and sexual history were combined. The results therefore suggest that any effects of Chlamydia antibodies on ectopic pregnancy are probably modulated through the combined effects of socio-demographic characteristics, sexual history and markers of previous pelvic infections.

The results indicate that having primary level of education was the strongest independent predictor of ectopic pregnancy in the investigated women, while the risks were also significantly elevated in women with three or more lifetime sexual partners and those with a previous history of vaginal discharge. Women with a lower level of education may be more likely to acquire genital tract infections that predispose them to increased risk of ectopic pregnancy. Although the women in the present study were not specifically asked questions on treatment sources following gynaecological infections, previous reports have suggested that women with lower levels of education were more likely to seek ineffective treatment from chemists and traditional healers than obtain effective evidence-based formal health sector treatment ${ }^{28}$. Thus less educated women may be more likely to present with the sequalae of chronic pelvic infections because of their greater likelihood to use ineffective methods of treatment for genital tract infections. Furthermore, the association between ectopic pregnancy, self-report of three or more lifetime sexual partners and vaginal discharge suggest that sexually transmitted organisms causing vaginal 
discharge are strongly associated with ectopic pregnancy.

Therefore, this study's finding is consistent with previous reports in suggesting that these proxies of sexually transmitted infections produce gynaecological symptoms that may be due to other genital tract infections rather than Chlamydia trachomati ${ }^{28-30}$. It is therefore plausible that in the women with ectopic pregnancy and had negative chlamydia serology, tubal damage may have been caused by other organisms. Other pathogens commonly implicated in the aetiology of gynaecological symptoms in Nigeria include Nessieria gonorrhea, Gram-negative organisms, viral agents and pathogenic anaerobes. Recent reports have also suggested that sexually transmitted Mycoplasma genitalium may be an important cofactor and/or the actual cause of salpingitis ${ }^{31}$. These infections may arise from puerperal sepsis, pelvic inflammatory disease, and post abortal sepsis. Indeed, a previous history of induced abortion was a significant predictor of ectopic pregnancy in this study, while a previous study had suggested a strong association between vaginal discharges and self-reports of induced abortion ${ }^{32}$. Again, a previous analysis of the risk factors for ectopic pregnancy provided evidence that previous self-report of induced abortion and a previous history of sexually transmitted diseases were associated with increased risk of ectopic pregnancy ${ }^{8}$. The results of this study therefore highlight the need for the continued search for the pathogenic agent most responsible for tubal disease and hence ectopic pregnancy especially in the light of emerging evidence of the increasing role of Mycoplasma genitalium. This hypothesis is supported by evidence suggesting that heat shock protein $60 \mathrm{kDa}$ antibodies might also be elicited by other micro-organisms?

Findings from ecological analyses such as this must be interpreted with caution as the analyses examine correlations between an exposure (Chlamydia infection) and an outcome (ectopic pregnancy). A potential problem is that these associations may be confounded by factors that have not been measured. These associations include sexual behaviour and the use of contraception ${ }^{19}$. The use of intrauterine devices increases the risk of an ectopic implantation ${ }^{8}$, if implantation occurs, while greatly reducing the probability of any pregnancy occurring. Thus women with IUCD were excluded from the study. The potential effects of confounders such as condom use and other aspects of sexual behaviour such as multiplicity of sexual partners were corrected for by logistic regression models.

This study relied on the use of serology which is less sensitive than culture and nucleic acid amplification tests in the diagnosis of Chlamydia infections. Currently, nucleic acid amplification tests are considered the method of choice in the diagnosis of Chlamydia infections because result specificities approach $100 \%{ }^{33}$. Unfortunately, these more sensitive tests are more expensive than serological tests and are also not available in many developing countries $^{28}$. However, the assay used here is in line with World Health Organization guidelines for laboratory diagnosis of Chlamydia trachomatis infection with performance characteristics reported as $73-83 \%$ sensitivity and 97-99\% specificity ${ }^{34}$.

Although it may be argued that the results of the present study, being a hospital based study, cannot be extrapolated to the general population, it is noteworthy to mention that the study was conducted in the two tertiary care hospitals in Benin City; UBTH and Central Hospital. The two hospitals attend to $>80 \%$ of the gynaecological case loads in Benin City and its environs. Therefore, allowing for a minimal margin of error, the results of this study may give a fairly true representation of the scenario of the association of Chlamydia antibodies with ectopic pregnancy in Benin City.

\section{Conclusion}

The present study demonstrated that a higher proportion of women with ectopic pregnancy had serological evidence of previous infection with Chlamydia trachomatis as compared to pregnant controls without previous ectopic pregnancy. However, the results of the study failed to show a strong independent association between Chlamydia antibodies and the risk of ectopic pregnancy. The low population attributable risk suggests that Chlamydia trachomatis infections are responsible for only a small proportion of the rising incidence of ectopic pregnancy observed in Benin City. The results of the multivariate logistic regression model show that having less than tertiary education, self-report of three or more lifetime sexual partners and a history of vaginal discharge were the strongest markers of ectopic pregnancy in these women. The implication is that these proxies of sexually transmitted diseases produce gynaecological symptoms that may be due to other genital tract infections rather than Chlamydia trachomatis. Therefore 
efforts to address these factors through the provision of sex education, prompt and effective treatment of sexually transmitted infections and improvement of health seeking behaviour for these infections will likely contribute to reducing the burden of ectopic pregnancy.

\section{Acknowledgments}

This study was partly supported with research fund made to the Women's Health and Action Research Centre (WHARC) by the Ford Foundation, New York, USA.

\section{References}

1. Gharoro EP, Igbafe AA. Ectopic Pregnancy revisited in Benin City, Nigeria: Analysis of 152 cases. Acta Obstet Gynaecol Scand. 2002; 81(12):1139-1143.

2. Selo-Ojeme DO, Onwude JL, Onwudiegwu U. Autotransfusion for ruptured ectopic pregnancy. International Journal of Gynaecology and Obstetrics. 2003; 80(2):103-110.

3. Aboyeji AP, Fawole AA, Olatinwo AWO; Trends in Ectopic pregnancy in Ilorin, Nigeria. Nig J Med Research. 2004; 4(1/2): 6-11.

4. Norman J. Epidemiology of female genital Chlamydia trachomatis infections. Best Practice and Research Clinical Obstetrics and Gynaecology. 2002; 16(6): 775-787.

5. Rajkhowa M, Glass MR, Rutherford AJ, Balen AH, Sharma V, Cuckle HS. Trends in the incidence of ectopic pregnancy in England and Wales from 1966 to 1996. BJOG. 2000;107(3):369-74.

6. Coste J, Bouyer J, Ughetto S, Gerbaud L, Fernandez H, Pouly JL et al. Ectopic pregnancy is again on the increase. Recent trends in the incidence of ectopic pregnancies in France (1992-2002). Hum Reprod. 2004;19(9):2014-8.

7. Trabert B, Holt VL, Yu O, Van Den Eeden SK, Scholes D. Population-based ectopic pregnancy trends, 1993-2007. Am J Prev Med. 2011;40(5):556-60.

8. Anorlu RI, Oluwole A, Abudu OO, Adebajo S. Risk factors for ectopic pregnancy in Lagos, Nigeria. Acta Obstetricia et Gynecological Scandinavia. 2005; 84(2); 184-188.

9. Sziller I, Witkin SS, Ziegert M, Csapo Z, Ujhazy A, Papp Z. Serological responses of patients with ectopic pregnancy to epitopes of the Chlamydia trachomatis $60 \mathrm{kDa}$ heat shock protein. Human Reproduction, 1998; 13(4): 1088-1093.
10. Abiodun MO, Ijaiya MA, Fawole AA, Jimoh AA. A study of serological evidence of prior Chlamydia trachomatis infection in patients with ectopic pregnancy in Ilorin, Nigeria. European Journal of Scientific Research, 2007; 16(2): 461-466.

11. Okunlola MA, Owonikoko KM, Adeyemi AS, Adeyemi-Doro FAB. Chlamydia serology and Ectopic pregnancy in Ibadan. Nigerian Medical Practitioner. 2009: 55(1-2): 13-15.

12. Brunham RC, Pealing R, MacLean I, Kosseim ML, Paraskevas M; Chlamydia trachomatis associated ectopic pregnancy: serologic and Histological correlates J. Infect Dis. 1992; 165(6): 1076- 1081.

13. Hillis SD, Owens LM, Marchbanks PA, Amsterdam LE, Mac Kenzie WR. Recurrent Chlamydia infections increase the risk of hospitalization for ectopic pregnancy and pelvic inflammatory disease. AM J Obstet Gynecol 1997; 176:103-7.

14. Bakken IJ, Skjeldestad FE, Lydersen S, NordbØ SA. Births and ectopic pregnancies in a large cohort of women tested for Chlamydia trachomatis. Sex Transm Disease. 2007; 34(10): 739743.

15. Andersen B, Østergaard L, Puho E, et al. Ectopic pregnancies and reproductive capacity after Chlamydia trachomatis positive and negative results; A histological follow-up study. Sex Transm Dis 2005; 32: 377-381.

16. Low N, Egger M, Sterne JA, Harbord RM, Ibrahim F, Lindblom B, Hermann B. Incidence of severe reproductive tract complications associated with diagnosed genital chlamydia infection; the Uppsala Women's cohort study. Sex Transm Infect. 2006; 82(3): 212-8.

17. Bakken IJ, Skjeldestad FE, NordbØ SA. Chlamydia trachomatis infections increase the risk for ectopic pregnancy; a population-based nested case-control study. Sex Transm Dis. 2007; 34(3): 166-9.

18. Bakken IJ. Chlamydia trachomatis and ectopic pregnancy; recent epidemiological findings. Current Opin Infect Dis. 2008; 21(1): 77-82.

19. Andersen B, Østergaard L, Thomsen R, Schønheyder H. Chlamydia trachomatis Infection and Risk of Ectopic Pregnancy. Sex Transm Dis. 2007;34(1): 59.

20. Coughlin SS, Benichou J, Weed DL. Attributable Risk Estimation in Case-Control Studies. Epidemiol Rev.1994; 16: 51-64. 
21. Kaelin MA, Bayona M. Attributable risk application in epidemiology. Working paper, the Young Epidemiology Scholars Program (YES). Robert Wood Johnson Foundation and College Entrance Examination Board: New York, USA. 2004: 8 - 11 .

22. Darougar S, Forsey T, Osoba AO, Dines RJ, Adelusi B, Coker GO. Chlamydia genital infection in Ibadan, Nigeria. A seroepidemiological survey. BrJ Vener Dis 1982; 58: 366-69.

23. Ville Y, Leruez M, Glowaczower E, Robertson JN, Ward ME. The role of Chlamydia trachomatis and Neissera gonorrhoea in the aetiology of ectopic pregnancy in Gabon. Br J Obstet 1991; 98(12):1260 -1266.

24. Akande VA, Hunt LP, Cahill DJ, Caul EO, Ford WC, Jenkins JM. Tubal damage in infertile women; prediction using chlamydia serology. Human reproduction. 2003; 18(9): 1841-1847.

25. Robertson J N, Hogston P, Ward M E. Gonococcal and chlamydial antibodies in ectopic and intrauterine pregnancy. British Journal of Obstetrics and Gynaecology. 1988;95: 7(1): 1- 16.

26. Svensson L, Mardh P A, Ahlgren M, Nordenskjold F. Ectopic pregnancy and antibodies to Chlamydia trachomatis. Fertility and Sterity. 1985;44:3 13-3 17.

27. Hill B, Shah S, Graham IH, Barakzai NS .The rising incidence of ectopic pregnancy in $\mathrm{Abu}$ Dhabi and maternal chlamydial infection. Journal of Obstetrics and Gynaecology. 1995; 15: 114-116.
28. Omo-Aghoja LO, Okonofua FE, Onemu SO, Larsen U, Bergstrom S. Association of Chlamydia trachomatis serology with tubal infertility in Nigerian women. J. Obstet. Gynaecol. Res. 2007; 33(5):688-695.

29. Cohen CR, Mugo NR, Astete SG, Odondo R, Manhart LE, Kiehlbauch JA, et al. Detection of Mycoplasma genitalium in women with laparoscopically diagnosed acute salpingitis. Sex Transm Infect 2005;81:463-6.

30. Clausen HF, Fedder J, Drasbek M, Nielsen PK, Toft B, Ingerslev HJ, et al . Serological investigation of Mycoplasma genitalium in infertile women. Hum. Reprod. 2001; 16:1866-1874.

31. Svenstrup HF, Fedder J, Kristoffersen SE, Trolle B, Birkelund S, Christiansen G. Mycoplasma genitalium, Chlamydia trachomatis, and tubal factor infertility-a prospective study. Fertil Steril. 2008;90(3):513-20.

32. Okonofua FE, Ako-Nai KA, Dighitoghi MD. Lower genital tract infections in infertile Nigerian women compared with controls. Genitourin Med 1995; 71:163 - 168 .

33. Watson EJ, Templeton A, Russell I, Paavonen J, Mardh PA, Stary A. et al. The accuracy and efficacy of screening tests for Chlamydia trachomatis; a systematic review. J. Med. Microbiol. 2002; 51: 1021 1031.

34. Black CM. Current Methods for Laboratory Diagnosis of Chlamydia trachomatis infections. Clinical Microbiology Review. 1997;10: 160-184. 